\title{
Front Matter: Volume 10306
}

, "Front Matter: Volume 10306," Proc. SPIE 10306, Future Directions and Applications in Photodynamic Therapy, 1030601 (21 January 1990); doi: 10.1117/12.2283663

SPIE Event: SPIE Institutes for Advanced Optical Technologies 6, 1990, San Diego, SPIE. California, United States 


\title{
Preface
}

The concept of the Institutes for Advanced Optical Technologies developed out of SPIE's desire to foster increased interaction and collaboration among researchers working in emerging optical technologies. The Institutes provide a forum for experts in these areas to analyze and document the state of the art and to point toward future trends and applications. Institute topics are selected for their timeliness as well as for their significance to future progress in the application of optics. Institute organizers invite selected experts to participate as paper contributors and discussion participants. It is intended that the interaction generated by the small-group structure in a retreat-like setting will foster productive discussions that are beyond the scope and possibility of a regular conference format.

Each Institute has two primary objectives: first, that the interactions and dialogue stimulate technical advancement, and second, that the publication of the Institute volume results in an authoritative collection of significant papers covering key topics in the field. While each editor and committee has unique criteria for determining the acceptability of contributions, it is intended that the Institute process itself will estabiish the worth and appropriateness of the individual contributions. Each contributor is asked to prepare a draft manuscript and circulate it to the other participants in advance of the Institute. The editor/chair organizes an agenda for discussing critical technical issues. The interactions and congenial discussions by the Institute members are the basis for the ensuing Institute volume. The final action of the Institute is to decide the scope of the volume and what material is to be included and what other material is to be added and by whom.

The Institute on photodynamic therapy, held January 19-21, 1990, in San Diego, addressed the future outlook and critical technical issues related to research and clinical development in PDT. The Institute forum gave the participants an opportunity to present and discuss in depth different approaches and expectations for the future development of PDT. It was especially fruitful to have the blend of technical interests represented by the participants-biochemists, clinicians, and engineers, all with a common interest in PDT.

This volume contains papers by the Institute participants and their research colleagues. Topics range from a review of the status of PDT clinical trials, studies into new photosensitizers, requirements in laser and fiber optic technologies for light delivery, to studies of the biological mechanisms behind PDT action.

\author{
Roy F. Potter \\ General Editor, SPIE Institutes for Advanced Optical Technologies
}
Future Directions and Applications in Photodynamic Therapy, edited by Charles J. Gomer
Proc. of SPIE Vol. 10306 (Vol. IS06), 1030601 - ( ) (1990) 2017 SPIE
CCC code: $0277-786 X / 17 / \$ 18 \cdot$ doi: $10.1117 / 12.2283663$




\section{Other publications in the SPIE Institutes for Advanced Optical Technologies series:}

Transformations in Optical Signal Processing, William T. Rhodes, James R. Fienup, Bahaa E. A. Saleh, Editors, 1984, SPIE Volume 373 (Out of print)

Optical and Hybrid Computing, Harold H. Szu, Editor, 1987, SPIE Volume 634

Photonics: High Bandwidth Analog Applications, James Chang, Editor, 1987, SPIE Volume 648

Large-Area Chromogenics: Materials and Devices for Transmittance Control, Carl M. Lampert, Claes G. Granqvist, Editors, 1990, Volume IS 4

Dosimetry of Laser Radiation in Medicine and Biology, Gerhard J. Müller, David H. Sliney, Editors, 1989, Volume IS 5 


\title{
Future Directions and Applications in Photodynamic Therapy
}

\section{Contents}

\author{
iii Preface \\ vii Institute Participants \\ ix Introduction \\ 1 Future of photodynamic therapy: is there one? \\ T. J. Dougherty, Roswell Park Cancer Institute \\ 5 Photodynamic therapy of human cancer: clinical status, potential, \\ and needs \\ S. L. Marcus, American Cyanamid Co. \\ 57 Photodynamic therapy: priorities for $\mathbf{1 9 9 0}$ \\ D. Kessel, Wayne State Univ. School of Medicine \\ 64 Oxygen monitoring during photodynamic therapy \\ B. J. Tromberg, Beckman Laser Institute and Medical Clinic, Univ. of \\ California/Irvine; S. Kimel, Technion-Israel Institute of Technology \\ (Israel); A. Orenstein, Sheba Medical Ctr. (Israel); J. S. Nelson, \\ M. W. Berns, Beckman Laser Institute and Medical Clinic, \\ Univ. of California/Irvine \\ 71 Syntheses of some new porphyrin photosensitizers for photodynamic \\ therapy \\ F-Y. Shiau, P. A. Liddell, M. G. H. Vicente, N. V. Ramana, \\ K. Ramachandran, S-J. H. Lee, Univ. of California/Davis; R. K. Pandey, \\ Oncologic Foundation of Buffalo; T. J. Dougherty, Roswell Park \\ Cancer Institute; K. M. Smith, Univ. of California/Davis \\ 87 Second-generation sensitizers: where are we and where should we be \\ going?
}

A. R. Morgan, D. Skalkos, Univ. of Toledo

107 Prospects of phthalocyanines as photosensitizers for the photodynamic therapy of cancer

J. E. van Lier, Univ. of Sherbrooke (Canada)

115 Chemical mechanisms of photodynamic action

C. S. Foote, Univ. of California/Los Angeles

127 Photosensitization with deep red light

M. A. J. Rodgers, Bowling Green State Univ.

139 Basic mechanisms and subcellular targets related to PDT

C. J. Gomer, A. Ferrario, M. Luna, N. Rucker, S. Wong, Childrens

Hospital of Los Angeles

153 Significance of vascular photosensitization in photodynamic therapy

B. W. Henderson, Roswell Park Cancer Institute 
167 Approaches to improved delivery of photosensitizers

B. Allison, A. M. Richter, F. Jiang, Univ. of British Columbia (Canada);

S. Jiang, D. Liu, Quadra Logic Technologies, Inc. (Canada); J. G. Levy,

Univ. of British Columbia (Canada)

177 New approaches to photochemotherapy: cationic sensitizers and multiagent combination therapies

A. R. Oseroff, Roswell Park Cancer Institute

195 Psoralen photobiology and photochemotherapy: perspectives and prospects

F. P. Gasparro, Yale Univ.

209 Photodynamic therapy and bone marrow transplantation

F. Sieber, Medical College of Wisconsin

219 Optical fiber-based diffuse reflectance spectrometer for noninvasive investigation of photodynamic sensitizers in vivo

B. C. Wilson, Hamilton Regional Cancer Ctr., McMaster Univ., and

Ontario Laser and Lightwave Research Center (Canada); T. J. Farrell,

M. S. Patterson, Hamilton Regional Cancer Ctr. and McMaster Univ.

(Canada)

233 On the physical rationale of photodynamic therapy

L. O. Svaasand, Univ. of Trondheim (Norway); C. J. Gomer, E. Morinelli, Childrens Hospital of Los Angeles

249 Photodynamic therapy of early cancer in the upper aerodigestive tract and bronchi: instrumentation and clinical results

G. Wagnières, Swiss Federal Institute of Technology (Switzerland);

P. Monnier, M. Savary, CHUV Hospital (Switzerland); P. F. Cornaz,

A. Châtelain, H. van den Bergh, Swiss Federal Institute of Technology

(Switzerland)

272 Optical-CCD system for imaging light and drug distributions in tumors for phototherapy

R. C. Straight, Univ. of Utah; P. M. N. Y. H. Go, Univ. Hospital of

Maastricht (Netherlands); R. E. Benner, J. A. Dixon, R. W. McClane, Univ. of Utah

$282 \quad$ Author Index

vi / SPIE Institute Series Vol. IS 6 (1990) 


\section{Institute Participants}

Michael W. Berns

Beckman Laser Institute and Medical Clinic

University of California-Irvine

1002 Health Sciences Road East

Irvine, CA 92715

Daniel R. Doiron

Laserguide, Inc.

51 Santa Felicia Drive

Santa Barbara, CA 93117

\section{Thomas J. Dougherty}

Roswell Park Cancer Institute

Department of Radiation Medicine

666 Elm Street

Buffalo, NY 14263

\section{Christopher S. Foote}

University of California-Los Angeles

Department of Chemistry and Biochemistry

Los Angeles, CA 90024

Francis P. Gasparro

Yale University

Department of Dermatology

Hunter Radiation Laboratory

333 Cedar Street

New Haven, CT 06510

\section{Charles J. Gomer}

Childrens Hospital of Los Angeles

USC School of Medicine

4650 Sunset Boulevard

Los Angeles, CA 90027

\section{Barbara W. Henderson}

Roswell Park Cancer Institute

Division of Radiation Biology

Elm and Carlton Streets

Buffalo, NY 14263

\section{David Kessel}

Wayne State University School of Medicine Departments of Pharmacology and Medicine 540 East Canfield

Detroit, Ml 48201

\section{Julia G. Levy}

Quadra Logic Technologies, Inc.

520 W. 6th Avenue

Vancouver, British Columbia

v52 4H5 Canada

Stuart L. Marcus

American Cyanamid Company

Medical Research Division

Lederle Laboratories

North Middletown Road

Pearl River, NY 10965

\section{Alan R. Morgan}

University of Toledo

Department of Chemistry

2801 West Bancroft Street

Toledo, OH 43606-3390

\author{
Allan R. Oseroff \\ Roswell Park Cancer Institute \\ Department of Dermatology \\ Elm and Carlton Streets \\ Buffalo, NY 14263
}

Michael A. J. Rodgers

Bowling Green State University

Center for Photochemical Sciences

Bowling Green, OH 43403

\section{Fritz Sieber \\ Medical College of Wisconsin \\ Department of Pediatrics \\ 870 l Watertown Plank Road \\ Milwaukee, WI 53226}

\section{Kevin M. Smith}

University of California-Davis

Department of Chemistry

Davis, CA 95616

Richard C. Straight
University of Utah
Laser Institute VAMC
500 Foothill Drive
Salt Lake City, UT 84132

Lars 0 . Svaasand

University of Trondheim

Norwegian Institute of Technology

Trond heim, N-7034

Norway

Bruce J. Tromberg

Beckman Laser Institute and Medical Clinic

University of California-Irvine

1002 Health Sciences Road East

Irvine, CA 92715-3054

\section{Hubert van den Bergh}

Swiss Federal Institute of Technology

Laboratory of Chemical Technology

Lausanne, $\mathrm{CH}-1015$

Switzerland

Johan E. van Lier

University of Sherbrooke

Faculty of Medicine

MRC Group in Radiological Sciences

Sherbrooke, Quebec J1H 5N4

Canada

Brian C. Wilson

Hamilton Regional Cancer Center

Department of Medical Physics

711 Concession Street

Hamilton, Ontario L8V lc3

Canada 


\section{Introduction}

Photodynamic therapy (PDT) is the treatment of malignant lesions with visible light following the systemic administration of tumor-localizing photosensitizers. The therapy takes advantage of the unique properties of laser-generated light sources and fiber optic delivery systems. Clinical applications of PDT in the treatment of solid tumors have a 15-year history, and a number of promising anecdotal studies have been reported. However, the first controlled Phase III clinical trials are only now being performed and the true potential of PDT has yet to be realized. Continued efforts to define photochemical and photophysical properties of photosensitizers used in PDT, as well as additional studies focused on identifying targets and mechanisms of action associated with PDT, should provide a solid foundation for understanding and exploiting the applications of this therapy. Likewise, the synthesis of new photosensitizers and the continued development of laser and dosimetry systems should play a significant role in the future refinement of PDT.

The goal of the SPIE Institute on Photodynamic Therapy was to provide an informal forum in which experts in various preclinical and clinical disciplines of PDT could debate current applications and future directions. As a result of this endeavor, the participants have written chapters for this book that provide new information on current research in PDT, as well as suggestions for future studies.

I'd like to thank Tom Dougherty, Barbara Henderson, and Lars Svaasand for their contributions as discussion leaders during the Institute, as well as all the participants for their contributions. I also thank Roy Potter for his support in bringing this Institute together. Finally, the financial assistance and organizational skills of SPIE are gratefully acknowledged. All of the participants express their sincere appreciation to SPIE and its staff for an extremely productive and enjoyable conference.

\section{Charles J. Gomer}

Childrens Hospital of Los Angeles

University of Southern California School of Medicine 